\title{
Attachment and the risk of mental health disorders during adolescence
}

\begin{abstract}
BACKGROUND
Attachment is one of the more important developmental aspects for predicting a person's level of adaptation and mental health. Previous research in this area suggests a relationship between insecure attachment and behavioural disorders, deviations as well as depression and other affective disorders. The goal of this study was to determine the relationships between adolescents' attachment patterns and aggression as well as internalisation and externalisation of problems - expressed as a tendency to assume the role of the victim or the perpetrator. We hypothesised that insecure patterns of attachment foster both aggression (as a personality feature) and a tendency towards mental health issues, through increasing the frequency of entering the role of a victim or a perpetrator.
\end{abstract}

PARTICIPANTS AND PROCEDURE

One hundred and twenty individuals aged 14-19 took part in the study, mainly high school and university students. The study was conducted in groups, with the consent of participants and their parents. The following methods were used to assess the variables: The Inventory of Parent and Peer Attachment (IPPA), the Buss-Perry Aggression Questionnaire (BPAQ) and the Mini Direct and Indirect Aggression Inventory (Mini-DIA).

\section{RESULTS}

Our results suggest that a relationship exists between aggressiveness and trust in the relationship with one's mother, as well as between hostility and alienation with regards to one's mother and father. Insecure attachment is a significant risk factor for mental health disorders, and it fosters both externalisation and internalisation behaviours.

\section{CONCLUSIONS}

We interpret the results as suggesting that attachment organisation plays an important role in a wide array of aspects of adolescent psychosocial development.

\section{KEY WORDS}

adolescence; externalizing; internalizing problems; aggressiveness

organization - Department of Clinical Psychology, Faculty of Education, Sociology and Health Sciences,

University of Zielona Góra, Zielona Góra, Poland

aUthors' Contributions - A: Study design - B: Data collection - C: Statistical analysis - D: Data interpretation .

E: Manuscript preparation · F: Literature search · G: Funds collection

CORRESPONDING AUTHOR - Prof. Iwona Grzegorzewska, Department of Clinical Psychology, Faculty of Education,

Sociology and Health Sciences, University of Zielona Góra, 2 Energetyków Str., 65-729 Zielona Góra, Poland,

e-mail: ia.g@interia.pl

TO CITE THIS ARTICLE - Grzegorzewska, I., \& Farnicka, M. (2016). Attachment and the risk of mental health disorders

during adolescence. Health Psychology Report, 4(1), 8-15. doi: 10.5114/hpr.2016.54545

RECEIVED 19.12.2014 · REVIEWED 28.12.2014 · ACCEPTED 02.08.2015 · PUBLISHED 10.10.2015 


\section{BACKGROUND}

The adolescent period is often considered critical to a person's development, due to an increased risk of onset or reinforcement of mental health disorders. It is a period when the foundations of a person's personality are laid, which lead to adaptive or maladaptive functioning (Hejmanowski, 1999). Many analyses of adolescence are concerned with identifying and analysing factors that have an influence on the first symptoms of mental health disorders (Radziwiłłowicz \& Macias, 2014). Nevertheless, it is a great challenge for both researchers and clinicians to identify patterns of behaviours which deviate from the norm in adolescents. To a large extent, this is a result of the nature of adolescence, where risk behaviours are treated as a normative element of development. Moreover, it is a time of emotional separation from parents and formation of intimate relations and interpersonal relationships (Obuchowska, 1996; Oleszkowicz, 1995). These changes often come with extreme emotional intensity, testing the adolescent's strategies for coping with stress and tension. Ineffective strategies may lead to crises and maladaptive functioning. Recent research indicates that these difficulties are compounded by mental health problems of parents, low sociodemographic status of the teenager's family, problems at school, troubled relationships with peers (deviant reference groups or sense of rejection), or high levels of antisocial behaviours (Dodge \& Pettit, 2003; Grzegorzewska, 2011). In these groups the deviant patterns of psychosocial functioning are associated with mental health disorders in the form of either externalisation or internalisation of problems (Kendall, 2004). Many studies regarding mental health disorders during adolescence emphasise that externalisation and internalisation of problems are often associated with the beginnings of personality disorders in young individuals - especially borderline personality and antisocial personality (Kobak, Zajac, \& Smith, 2009). The attempt to further identify characteristic symptoms and establish the processes and mechanisms responsible for their formation is a central element of research in the area. Apart from interpersonal processes (such as fear of rejection and instability of relations), impaired regulation of affect and weakened ability to control impulses are factors which play a key role in the formation of tendencies towards mental health disorders (Clarkin \& Posner, 2005; Crick, Murray-Close, \& Woods, 2005). Hostility (personality feature) and/or inappropriately intense anger (exhibited at the behavioural level) lay the foundation of such malfunctioning (McGirr, Paris, Lesage, Renaud, \& Turecki, 2007). Anger may be expressed as externalised behaviours (frequent displeasure, oppositional behaviour, getting into physical fights) or internalisation (intense dysphoria, irritability, anxiety, emotional instability).
Literature discussing initiating and reinforcing factors of mental health in adolescents suggests that the formation of early emotional relationships of a child, and their influence on future development, are among the most important issues in the context of differentiation of developmental pathways (Sroufe, Carlson, \& Shulman, 1993; Grzegorzewska, 2015). A constantly developing body of research based on Bowlby's theory of attachment (Bowlby, 1988) suggests that though behaviours related to attachment are most visible and intense during early developmental periods, they can be observed throughout one's entire life. According to this theory, the quality of current attachment of an adolescent individual in their relations with parents and their skills resulting from secure attachment formed in the early childhood period are key features in allowing one to cope with problem solving in the adolescence period. This theory focuses on individual and relational developmental processes and thus not only offers an understanding of normative and pathological behaviours during adolescence, but also equips clinicians with essential intervention models. Such models are based on the development of crucial skills that can be impaired as a result of a dysfunctional parent-child relationship (cf. Plopa, 2014).

Attachment is one of the more important developmental aspects in determining levels of adaptation and mental health, which is why, to this day, many theoretical models for empirical studies on children have been based on the attachment theory (Weinfield, Sroufe, Egeland, \& Carlson, 2008; Bakermans-Kranenburg, van Ijzendoorn, \& Juffer, 2003). In contrast to the earlier developmental periods, the meaning and importance of the attachment construct for adolescents' functioning is described mostly in theoretical considerations, and is still the subject of a limited number of empirical studies. However, it is highly likely that the pattern of attachment is correlated with many aspects of the psychosocial functioning of adolescents. This is both due to the fact that it mirrors the basic aspects of formation of social relations and because it may be associated with features of the current parent-child relationship (Allen \& Land, 1999; Bowen, 1978). If attachment really is related to various aspects of the psychosocial functioning of adolescents, then it may potentially explain the continuity (between generations, and in a life cycle) of mental health problems, which often have their onset in adolescence (e.g. depression, behaviour disorders, aggression). Previous research in this area suggests a relationship between insecure attachment and depression (Kobak, Sudler, \& Gamble, 1991; Allen, Porter, McFarland, McElhaney, \& Marsh, 2007) as well as other affective disorders (Rosenstein \& Horowitz, 1996). In relation to mental health disorders expressed as externalising behaviours, it is suggested that insecure patterns of attachment may
Attachment and disorders in adolescence 
serve as predictors of anger and hostility towards one's parents, and thus decrease behavioural control, which is the main buffer of deviant behaviours among teenagers (Greenberg \& Speltz, 1988; Patterson, DeBaryshe, \& Ramsey, 1989). A relationship has been shown between attachment and behaviour disorders (Rosenstein \& Horowitz, 1996) and deviant behaviours (Allen et al., 1996, 2007).

The present research assessed the relationship between attachment in the adolescent's relations with their mother and father and three main indices of psychosocial functioning: 1. Aggression as a personality feature, 2. Presence of externalisation of problems (in the form of readiness to be the perpetrator of aggression), and 3 . The presence of internalisation of problems - in the form of entering the role of a victim. Potential relations between attachment and the listed aspects of adolescents' functioning discussed above suggest how broad and deep the relations can be between them in such an important period of development as adolescence.

In the context of the above considerations, our main research questions were formed, concerned with assessment of the role of attachment as a predictor of mental health disorders during adolescence. We conducted a verification of the assumptions about the role of insecure patterns of attachment in the shaping of aggression as a personality feature that is relatively constant and stable over time. The analyses also took into account the relationships between attachment and the readiness of a teenager to assume the role of a perpetrator (symptom of externalisation) or a victim (symptom of internalisation of problems).

Two research hypotheses were made:

1. Insecure attachment, exhibited as a high index of alienation in the relationship with one's parents as well as a low level of communication and trust, favours aggression as a personality feature.

2. Insecure attachment fosters mental health disorders, in the direction of both externalisation and internalisation of problems.

\section{PARTICIPANTS AND PROCEDURE}

\section{STUDIED GROUP}

One hundred and twenty individuals aged between 16 and 19 took part in the study - 72 girls $(60 \%)$ and 48 boys ( $40 \%)$. The study was conducted in groups, with consent of the teenagers and their parents (if the teenagers were underage). Consent was obtained at school meetings. The sampling was purposive, with biological age being between 16 and 19 as a criterion. This criterion was chosen because of the changes in mental functioning and social relations associated with fulfilment of developmental tasks characteris- tic for that period of life. The study was conducted in groups during classes, and under the supervision of the school psychologist. Groups of students were randomly selected from previously randomly chosen secondary schools (comprehensive, technical and vocational).

\section{MEASUREMENT TOOLS}

Two subscales of the experimental version of Armsden and Greenberg's Inventory of Parent and Peer Attachment (IPPA) were used to assess attachment. The scale was developed to assess the affective-cognitive patterns of attachment of young people as sources of a sense of security. The IPPA is based on the theory of attachment initially formed by Bowlby and recently expanded by other researchers. Three dimensions of attachment are assessed: level of trust, quality of communication and scope of anger and alienation. Each subscale contains 25 items scored on a 5-point Likert scale. Results can fall between 25 and 100 points - 10-50 points for the Trust subscale, 9-45 points for the Communication subscale, and 6-30 for the Alienation subscale. The Cronbach $\alpha$ reliability coefficients for the subscales range between .87 and .89. Psychometric measurements of accuracy gave satisfactory results. The test is widely used in the USA (Murray \& Greenberg, 2000). In Poland it has been used in a small number of studies (Grzegorzewska, 2013).

The Buss-Perry Aggression Questionnaire (Buss \& Perry, 1992) was used to assess individual differences in aggressive personality. The 29-item scale is composed of four subscales: physical aggression, verbal aggression, anger, and hostility. It is a 5-point scale which ranges from 1 (extremely uncharacteristic of me) to 5 (extremely characteristic of me). The questionnaire contains 4 factors: Physical Aggression, Verbal Aggression, Anger, and Hostility. Internal consistency of the four subscales and total score range from .72 (Verbal Aggression) to .89 (Total BPAQ score). Retest reliability for the BPAQ over nine weeks is also satisfactory (correlations ranged from .72 for Anger to .80 for Physical Aggression and for the total score) (Buss \& Perry, 1992).

Information about externalising and internalising problems was gathered with the Mini Direct and Indirect Aggression Inventory (Mini-DIA). The Mini-DIA is an abbreviated version of the Direct-Indirect Aggression Scales (Österman \& Björkqvist, 1998), developed as a less time-consuming version of the original instrument. It has been shown to yield similar results to the original scales. Instead of consisting of multiitem scales measuring physical, verbal, and indirect aggression, the scales are instead single-item, and the types of aggression are defined to the respondents as follows: 1) physical aggression: "another pupil has, 
for instance, hit, kicked, or pushed you"; 2) verbal aggression: "another pupil has, for instance, screamed at you, or said hurtful things about you or [added in Iran] your family"; 3) indirect aggression: "another pupil has spread malignant gossip about you, spread untrue stories about you, or tried to freeze you out”. Respondents then state, on a five-point scale, ranging from 0 (never) to 4 (often), to what extent they have been exposed to these. There is both a Victim and a Perpetrator Version of the Mini-DIA.

\section{RESULTS}

\section{VERIFICATION OF THE HYPOTHESES}

Hypothesis 1: Insecure attachment, exhibited as high Alienation (in their relationship with their parents) scores and low Communication and Trust scores, favours the personality feature of aggressiveness among adolescents.

The results suggest a significant correlation between general aggression levels and the trust-mother dimension (Pearson's $r=.39, p=.001$ ). Moreover, it was possible to observe specific relationships between the anger and trust dimensions in the relationship with the mother (Pearson's $r=.57, p=.001$ ), alienation in the relationship with the mother $(r=.24, p=.050)$ and father $(r=.24, p=.050)$, as well as both parents $(r=.28, p=.010)$. The results also suggest that trust in the relationship with the mother is positively correlated with all dimensions of aggression except for hostility (physical aggression $r=.20, p=.050$; verbal aggression $r=.28, p=.010$; hostility $r=.57, p=.001$; general levels of aggression $r=.39, p=.001)$. It is worth noting that there was a positive correlation between alienation in the relationship with the father and verbal aggression $(r=.22, p=.050)$. The results indicate that trust in the relationship with the mother may be of key importance in explaining the general levels of aggression among adolescents. A regression model $\left(R^{2}=.16, d f=1, F=21.60, \alpha<.01\right.$, $\beta=.40$ ) suggested that in over $16 \%$ of cases the levels of aggression are determined by trust in the relationship with the mother.

In view of the obtained correlations between different dimensions of attachment and the 'Anger' component of aggression, it was verified that attachment is an important predictor of anger. A regression model was built (hierarchic analysis, $R^{2}=.35$, $d f=1, F=58.07, \alpha<.01, \beta=.59)$; it suggests that almost $35 \%$ of variance for the anger variable (one of the dimensions of the aggressiveness personality feature) is determined by trust in the relationship with the mother.

This result is surprising, because it is generally believed that trust is a dimension favouring formation of bonds and indicating a safe relationship. Hence it is surprising that it can predict aggression and anger. One of many reasons for this result may be the fact that the participants are at an age where there is a need to redefine their relationship with their parents.

Hypothesis 2: Insecure attachment is a significant risk factor for mental health disorders and it favours both externalisation and internalisation behaviours.

Internalisation behaviours exhibited as control over impulses and emotions, including aggression or anger, and assuming the role of a victim, are related to the levels of trust in one's relationship with one's parents, and the levels of alienation in one's relationship with one's mother. The obtained regression model with values $R^{2}=.11, d f=4, F=3.33$, $\alpha=.01, \beta=-.21$ (trust in relationship with mother), $\beta=.27$ (alienation in relationship with mother), $\beta=-.18$ (trust in relationship with father) means that the exhibition of internalisation behaviours increases with lowered trust in one's relationship with one's mother and father and higher alienation in the relationship with one's mother. In the case of correlates of externalisation behaviours, a clear relationship was observed with trust and alienation in the relationship with one's mother $\left(R^{2}=.09, d f=2, F=3.61\right.$, $\alpha<.05, \beta=-.26$ ).

These results suggest that trust, especially in one's relationship with one's mother, is a key protective factor in the case of exhibiting externalisation and internalisation behaviours. However, in the case of internalisation behaviours, the youths' situation seems even more difficult. Not only do they lack a bond based on trust, but they also feel alienation and hostility in their relationship with their mother.

The specifics of determinants for individuals characterised by low levels of externalisation and internalisation disorders were also investigated. It was found that trust is the best predictor of anger among people with no clear disorders $\left(R^{2}=.59, d f=4\right.$, $F=16.92, \alpha<.01, \beta=.72$ ); therefore with the increase of trust towards one's parents, the levels of externalisation and internalisation disorders drop.

\section{DISCUSSION}

Analysis of the results led us to a few important conclusions. Firstly, there is a correlation between attachment and aggression. As assumed, the patterns of attachment in the period of adolescence were correlated with aggression as a personality feature. However, not all of the predicted correlations were confirmed. It was hypothesised that insecure attachment (understood as e.g. high levels of hostility and alienation in relations to one's parents as well as low levels of communication and trust) would be positively correlated with aggression as a personality feature. The results were quite surprising. Aggres-
Attachment and disorders in adolescence 
sion was significantly positively correlated with high levels of trust in the relationship with one's mother and father. Whereas the correlation between aggression and high levels of hostility and alienation in one's relations with both parents was predicted, the positive correlation with high levels of trust towards one's mother was highly surprising. Correlations between the remaining dimensions of attachment (bond and communication) and the investigated dependent variable were also not confirmed.

Iwona

Grzegorzewska, Marzanna

Farnicka Alienation indicates the presence of a sense of isolation, hostility and rejection in the adolescent's attachment relations with parents. In combination with low levels of communication and trust, it suggests formation of insecure attachment patterns, which in consequence may influence the formation of mental health disorders. From the point of view of attachment theory, adolescence is critical for the formation of cognitive, emotional and behavioural changes. Adolescents develop their own views about the world and other people. They separate themselves from their parents. Moreover, the transition into adolescence forces them to modify their relations with their parents, and seeking a balance between closeness and autonomy becomes the goal. In this period, young people actively seek increased independence and autonomy within their family. However, this does not mean breaking attachment relations with parents: the autonomy of youths is not formed at the expense of bonds and attachment; rather it is a development based on closeness, safety and stability in one's relationship with one's parents (Allen, Hauser, Bell, \& O'Connor, 1994). In other words, teenagers can safely seek behaviours that explore their own independence, because they know that their parents will keep the attachment levels constant, and they will receive support in situations when they actually need it. Current results that suggest a high correlation between perceived hostility and alienation in attachment relations with parents, and a high level of aggression as a personality feature, support these considerations. We can also distinguish an insecure style of attachment that is based on avoidance and ambivalence (Vivona, 2000), wherein adolescents scoring higher on the alienation scale (in comparison to the trust and communication scales) present a style based on avoidance. It can therefore be suspected that avoidant, insecure patterns of attachment may foster the development of unfavourable personality features (aggression), which are disadvantageous for mental health. Of course, longitudinal research is required to confirm such a suggestion.

The obtained correlations between intense hostility and alienation and aggression had been predicted, and are in line with previous research (Farnicka \& Grzegorzewska, 2015). The positive correlation between trust (as a dimension of attachment) and aggression (16\% explanation of variance for the aggressiveness variable) is very surprising, because the opposite was expected. Interestingly, this correlation occurs only in relation to the mother, not both parents.

From the reports of Vivona (2000) we know that insecure patterns of attachment based on ambivalence are characterised by lower levels of trust and higher levels of communication and alienation. Accordingly, one ought to assume that trust in one's relationship with one's mother would favour low levels of aggressiveness. However, this seemingly surprising result has a theoretical explanation, especially in the context of the adolescent period. On one hand, the result can be explained by the process of transformation of relationships (from dependent to independent), which is characteristic of the adolescent period. The previously close contact with one's mother causes a strong dissonance between the actual and the expected relationships. Paradoxically, a seemingly good relationship with one's mother, based on the conviction that one's needs are understood and respected, may be a source of anger and disturb the picture of an independent and separated teenager. This dissonance between the expected and the perceived situation in the relationship with one's mother may increase the levels of anger and explain the test score. A developmental approach to this problem, based on research on the crisis of adolescence, was discussed by Oleszkowicz, who pointed out the problem of closeness in the relationship with one's parents and achieving independence and a sense of self-reliance (Oleszkowicz, 2006). Also, Liberska (2007) discussed extension of the identity moratorium as well as the failure of youths to make attempts at separation. It can be therefore suspected that high levels of trust in one's relationship with one's mother may be perceived by the teenager as an obstacle in the process of individuation and identity shaping. During the adolescent period, the dual role of the parent (providing support and safety as well as supporting separation attempts) has to be redefined in accordance with the current needs of the child. Attachment patterns in this period are a result of the mutual ability of the parents and the teenager to redefine attachment bonds, taking into account the process of individuation, and changes occurring at the cognitive, emotional and social level. In line with attachment theory, such a re-definition is possible mostly due to the exchange between the parent and the adolescent in terms of communicating about one's emotional states, and the thought exchange of each member of the dyad (Rosenblum \& Lewis, 2006). Because the increasing need of separation from parents is a striking aspect of the individuation process in the period of adolescence, the perceived excessive closeness in the relationship with one's parents, especially the mother (usually the main figure of attachment), may be interpreted as a symptom of trust, which in turn may lead to the intensification of anger. This issue re- 
quires further exploration, especially given that trust in attachment relations between a teenager and their parents (understood as availability and acceptance of current needs) is key to the formation of secure attachment in that period (Larson, Richards, \& Moneta, 1996; Gamble \& Roberts, 2005).

On the other hand, a good relationship with one's mother can also influence other personality features of a teenager - those that increase the ability to express one's true desires, thoughts and qualities. This could mean an 'overrepresentation' of the aggressiveness feature in the group of people characterised by secure patterns of attachment (cf. Allen, Moore, Kuperminc, \& Bell, 1998; Dubois-Comtois et al., 2013). The role of verbalisation and mentalisation in the process of emotional control of behaviours was also stressed by Cierpiałkowska (2014) and Frączek (1979).

Secondly, based on the present research, one can see the significant role of trust in determining susceptibility to disorders. It is worth noting that the current results indicate that trust in one's relationship with one's mother is the most important aspect of attachment from the point of view of positive adaptation and mental health. Particularly, it turned out that secure attachment (especially high levels of trust and low levels of alienation) positively correlate with low levels of externalisation and internalisation of disorders, expressed as victim/perpetrator types of behaviour. One can therefore infer (at least indirectly) about the protective role of attachment (especially in one's relationship with one's mother) in the period of adolescence. Attachment theory suggests that many significant changes at the cognitive, emotional and social levels occur in this period, and these changes have an impact on the re-definition of one's relationship with one's parents (Dubois-Comtois, Cyr, Pascuzzo, Lessard, \& Poulin, 2013; Plopa, 2014). It is worth noting that, for instance, at the cognitive level, the development of abstract thinking and the skills to differentiate oneself from others facilitates teenagers' understanding that some people are better able to fulfil their needs than others (Allen, 2008). Cognitive skills make it easier for adolescents to re-evaluate their representation of the attachment figure. It is however more probable that individuals with insecure attachment are more prone to false perceptions and cognitive dysfunction in affective situations, and thus they are more susceptible to the emergence of externalisation and/or internalisation symptoms (Dwyer et al., 2010). The same applies to changes at the emotional level. Intense and unstable affective states in teenagers may readily activate attachment patterns, leading to the sense of being emotionally submerged and powerless in difficult situations (Rosenblum \& Lewis, 2006). The emotional instability of adolescents, in combination with the individuation needs, leads to seeking support from parents in difficult situations, which emphasises the significance of proper communication with one's parents (Ackard, Neumark-Sztainer, Story, \& Perry, 2006). It is likely that this mechanism plays a special role in the case of adolescents with insecure patterns of attachment and who are more susceptible to behavioural and emotional disorders (Margolese, Markiewicz, \& Doyle, 2003; Marsh, McFarland, Allen, McElhaney, \& Land, 2006).

Finally, based on the current results, one can say that trust in the relationship with one's mother (as the basic figure of attachment) influences, most of all, the ability to control impulses and cope with stress. The results suggest that in the group of individuals with low levels of disorders, trust is the strongest predictor of aggressiveness. This means that despite the intensity of the anger of an individual with a secure pattern of attachment (e.g. high levels of trust in relations with a figure of attachment), such individuals are in a low-risk group for the occurrence of mental health disorders exhibited as internalisation and/ or externalisation types of behaviours. These results are in line with previous research (Allen et al., 1998) suggesting that secure attachment is associated with general good psychosocial functioning of teenagers, including low levels of internalisation behaviours (depression) and low levels of deviant behaviours.

In summary, one can say that secure patterns of attachment are not a straightforward indicator of positive relations between teenagers and their parents. Rather, the results suggest that the patterns of attachment play an indirect role in shaping specific personality features and skills of fulfilment and control over specific needs of adolescence, including the need for individuation and safety. This may be because attachment patterns mirror the internal operation models, through which one can perceive oneself as incapable, or even unworthy of fulfilment of the attachment needs in relations with a figure of attachment (Bowlby, 1988). Therefore, a specific configuration within attachment associated with high levels of alienation and trust in one's relationship with one's mother could be a risk indicator. In this case, trust and alienation could be evidence of perceived hostility from one's mother. Thus, the exhibited internalisation type disorder could indicate an impaired contact process in the parent-teenager dyad.

\section{CONCLUSIONS}

Though the influence of attachment patterns on the functioning of an individual may be assessed throughout the whole life, most research deals with the early years of life. The results presented here, despite being based on a cross-sectional model, suggest the need to extend the research to other periods of development. Even though we cannot directly infer causal relationships based on the results of the current research, they do suggest that attachment continues to influence the
Attachment and disorders in adolescence 
psychopathology of an individual in subsequent periods of life. In particular, the results stress the need to focus on adolescence, given the peculiarities of this period, when discussing the relationship between attachment and mental health disorders. It was confirmed that secure attachment is generally a factor that promotes mental health and low levels of psychopathological symptoms. However, interestingly, trust and alienation in the relationship with one's parents (especially the mother) played the greatest role in shaping aggressiveness and the readiness to enter the role of a perpetrator or a victim. It can therefore be accepted that despite the fact that there is a positive correlation between trust towards one's mother and high levels of aggressiveness, at the same time, trust facilitates control over one's own aggressiveness, lowering the risk of psychopathology. On the other hand, alienation is associated with mental health disorders. The current results (in particular the significance of alienation and hostility in one's relationship with one's parents, alongside low levels of trust, for the risk of emotional and behavioural disorders among adolescents) may be of importance for the direction of future research on the specific configuration of elements and dimensions of attachment and their significance for the development of mental health disorders, as well as for intervention and therapy.

\section{ReferenCEs}

Ackard, D. M., Neumark-Sztainer, D., Story, M., \& Perry, C. (2006). Parent-child connectedness and behavioral and emotional health among adolescents. American Journal of Preventive Medicine, 30, 59-66.

Allen, J. P. (2008). The attachment system in adolescence. In: J. Cassidy \& P. R. Shaver (eds.), Handbook of Attachment Second Edition: Theory, Research, and Clinical Applications (pp. 419-435). New York, USA: The Guilford Press.

Allen, J. P., Hauser, S. T., Bell, K. L., \& O'Connor, T. G. (1994). Longitudinal assessment of autonomy and relatedness in adolescent-family interactions as predictors of adolescent ego development and self-esteem. Child Development, 65, 179-194.

Allen, J., Hauser, S., O'Connor, T., Bell, K., \& Eickholt, C. (1996). The connection of observed hostile family conflict to adolescents' developing autonomy and relatedness with parents. Development and Psychopathology, 8, 425-442.

Allen, J. P., Moore, C. M., Kuperminc, G. P., \& Bell, K. (1998). Attachment and adolescent psychosocial functioning. Child Development, 69, 1406-1419.

Allen, J. P., \& Land, D. (1999). Attachment in adolescence. In: J. Cassidy \& P. R. Shaver (eds.), Handbook of attachment theory and research (pp. 319-335). New York: Guilford.
Allen, J. P., Porter, M., McFarland, C., McElhaney, K. B., \& Marsh, P. (2007). The relation of attachment security to adolescents' paternal and peer relationships, depression, and externalizing behavior. Child Development, 78, 1222-1259.

Bakermans-Kranenburg, M. J., van Ijzendoorn, M. H., \& Juffer, F. (2003). Less is more: meta-analyses of sensitivity and attachment interventions in early childhood. Psychology Bulletin, 129, 195-215.

Bowen, M. (1978). Family therapy in clinical practice. New York: Jason Aronson.

Bowlby, J. (1988). A secure base. Clinical applications of attachment theory. London: Routledge.

Buss, A. H., \& Perry, M. P. (1992). The aggression questionnaire. Journal of Personality and Social Psychology, 63, 452-459.

Cierpiałkowska, L. (2014). Emotional dysregulation and aggression among people with borderline personality disorders. Lecture given during the XXXVII CICA International Conference on Conflict and Aggression, Zielona Góra, 22-26 June.

Clarkin, J. F., \& Posner, M. (2005). Defining the mechanisms of borderline personality disorder. Psychopathology, 38, 56-63.

Crick, N. R., Murray-Close, D., \& Woods, K. (2005). Borderline personality features in childhood: A short-term longitudinal study. Development and Psychopathology, 17, 1051-1070.

Dodge, K. A., \& Pettit, G. S. (2003). A biopsychosocial model of the development of chronic conduct problems in adolescence. Developmental Psychology, 39, 349-371.

Dubois-Comtois, K., Cyr, C., Pascuzzo, K., Lessard, M., \& Poulin, C. (2013). Attachment theory in clinical work with adolescents. Journal of Child and Adolescence Behavior, 1, 2-8.

Dubois-Comtois, K., Cyr, C., Pascuzzo, K., Lessard, M., \& Poulin, C. (2013). Attachment theory in clinical work with adolescents. Journal of Child and Adolescent Behaviour, 1, 111. doi: 10.4172/jcalb. 1000111

Dwyer, K., Fredstrom, B., Rubin, K. H., Rose-Krasnor, L., Booth-LaForce, C. L., \& Laursen, B. (2010). Attachment, social information processing, and friendship quality of early adolescent girls and boys. Journal of Social and Personal Relationships, 27, 91-116.

Farnicka, M., \& Grzegorzewska, I. (2015). Intrapersonal correlates of aggression in adolescents: determinants of undertaking the role of the perpetrator and the victim. Current Issues in Personality Psychology, 3, 25-35.

Frączek, A. (ed.). (1979). Studia nad psychologicznymi mechanizmami czynności agresywnych [Studying psychological mechanisms of aggressive actions]. Warszawa: PAN.

Gamble, S. A., \& Roberts, J. E. (2005). Adolescents' perception of primary caregivers and cognitive style: the roles of attachment security and gender. Cognitive Therapy and Research, 29, 123-141. 
Greenberg, M. T., \& Speltz, M. L. (1988). Attachment and the ontogeny of conduct problems. In: J. Belsky \& T. Nezworski (eds.), Clinical implications of attachment (pp. 177-218). Hillsdale, NJ: Erlbaum.

Grzegorzewska, I. (2011). Dorastanie w rodzinach $z$ problemem alkoholowym [Growing up in families with alcohol problems]. Warszawa: Wydawnictwo Naukowe Scholar.

Grzegorzewska, I. (2013). Odporność psychiczna dzieci alkoholików [Mental resiliency in children of alcoholics]. Warszawa: Wydawnictwo Naukowe Scholar.

Grzegorzewska, I. (2015). Negative life events, coping and mental health in middle childhood. Health Psychology Report, 3, 201-209.

Hejmanowski, S. (1999). Tożsamość młodzieży w ponowoczesnym świecie [Youth identity in the post-modern world]. In: T. Rzepa (ed.), W poszukiwaniu tożsamości [On a search for identity] (pp. 39-51). Szczecin: Wyd. Naukowe Uniwersytetu Szczecińskiego.

Kendall, P. C. (2004). Zaburzenia okresu dzieciństwa $i$ adolescencji [Disorders of childhood and adoescence]. Gdańsk: GWP.

Kobak, R. R., Sudler, N., \& Gamble, W. (1991). Attachment and depressive symptoms during adolescence: A developmental pathways analysis. Development and Psychopathology, 3, 461-474.

Kobak, R., Zajac, K., \& Smith, C. (2009). Preoccupied states of mind and trajectories of hostile-impulsive behavior: implications for the development of personality disorders. Developmental Psychopathology, 21, 839-851.

Larson, R. W., Richards, M. H., \& Moneta, G. (1996). Changes in adolescents' daily interactions with their families from ages 10 to 18: Disengagement and transformation. Developmental Psychology, 32, 744-754.

Liberska, H. (2007). Specyfika ksztattowania się tożsamości wspótczesnej mtodzieży. Z zagadnień psychologii rozwoju człowieka. Tom 1 [Characteristics of identity formation in modern youth. Discourses in human developmental psychology. Vol. 1] (pp. 143-158). Lublin: Towarzystwo Naukowe KUL.

Margolese, S. K., Markiewicz, D., \& Doyle, A. B. (2005). Attachment to parents, best friend, and romantic partner: predicting different pathways to depression in adolescence. Journal of Youth and Adolescence, 34, 637-650.

Marsh,P.,McFarland,F.C.,Allen,J.P., McElhaney, K.B., \& Land, D. (2003). Attachment, autonomy, and multifinality in adolescent internalizing and risky behavioral symptoms. Developmental Psychopathology, 15, 451-467.

McGirr, A., Paris, J., Lesage, A., Renaud, J., \& Turecki, G. (2007). Risk factors for suicide completion in borderline personality disorder: A case-control study of cluster B comorbidity and impulsive aggression. Journal of Clinical Psychiatry, 68, 721-729.

Murray, C., \& Greenberg, M. T. (2000). Children's relationship with teachers and bonds with school an investigation of patterns and correlates in middle childhood. Journal of School Psychology, 38, 423-445.

Obuchowska, I. (1996). Drogi dorastania [The trajectories of developments]. Warszawa: WSiP.

Oleszkowicz, A. (1995). Kryzys mtodzieńczy - istota i przebieg [The crisis of adolescence - its substance and course]. Wrocław: Wydawnictwo UWR.

Oleszkowicz, A. (2006). Bunt mtodzieńczy. Uwarunkowania. Formy. Skutki [The adolescent rebel. Determinants. Forms. Consequences]. Warszawa: Wydawnictwo Naukowe Scholar.

Österman, K., \& Björkqvist, K. (1998). The mini direct indirect aggression inventory. Finland: Abo Akademii.

Patterson, G. R., De Baryshe, B. D., \& Ramsey, E. (1989). A developmental perspective on antisocial behavior. American Psychologist, 44, 329-335.

Radziwiłłowicz, W., \& Macias, M. (2014). Self-esteem and achievement motivation level in overweight and obese adolescents. Health Psychology Report, 2, 132-143.

Rosenblum, G. D., \& Lewis, M. (2006). Emotional development in adolescence. In: G. R. Adams M. D. \& Berzonsky (eds.), Blackwell Handbook of Adolescence (pp. 269-289). Malden, MA: Blackwell Publishing.

Plopa, M. (2014). Więzi rodzinne i małżeńskie w perspektywie teorii przywiązania [Familial and marital bonds in the perspective of the Attachment theory]. In: I. Janicka \& H. Liberska (eds.), Psychologia rodziny [Family Psychology] (pp. 141-164). Warszawa: PWN.

Rosenstein, D. S., \& Horowitz, H. A. (1996). Adolescent attachment and psychopathology. Journal of Consulting and Clinical Psychology, 64, 244-253.

Sroufe, L. A., Carlson, E., \& Shulman, S. (1993). Individuals in relationships: Development from infancy through adolescence. In: D. Funder, R. Parke, C. Tamlinson-Keasey, \& K. Widaman (eds.), Studying lives through time (pp. 315-342). Washington: American Psychological Association.

Vivona, J. M. (2000). Parental attachment styles of late adolescents: Qualities of attachment relationships and consequences for adjustment. Journal of Counseling Psychology, 47, 316-329.

Weinfield, N. S., Sroufe, L. A., Egeland, B., \& Carlson, E. A. (2008). Individual differences in infant-caregiver attachment: Conceptual and empirical aspects of security. In: J. Cassidy, P. R. Shaver (eds.), Handbook of Attachment: Theory, Research, and Clinical Applications (pp. 78-101). New York, USA: The Guilford Press.
Attachment and disorders in adolescence 